\title{
PERSPECTIVES
}

\section{REFLEXIVITY IN TEACHING AND RESEARCHING ORGANIZATIONAL STUDIES}

\section{INTRODUCTION}

We live in a world where we are experiencing an increasing number of environmental disasters, social injustice, corporate scandals, and questionable leadership ethics. The issue I would like to address in this article is how we, as educators and researchers, might respond to or engage proactively with these issues. One approach is encouraging our students to become more reflexive, and to become more reflexive ourselves as researchers. I believe that reflexivity is becoming an increasingly important resource in organization studies. Defined as questioning taken-for-granted assumptions, practices, policies, and so on, reflexivity offers a way of developing more critical and responsible approaches to our intellectual strategies and to practical activities within the academic and corporate world. I will begin by summarizing some of the criticisms of business school education and the challenges we face as researchers and go on to define and discuss how reflexivity can help us engage with these criticisms in a productive manner.

\section{Criticism}

Moral and political philosopher, Alasdair Maclntyre (1981) argued that managers are generally perceived as engaging in value-neutral activities that are concerned with rational and efficient means rather than in any moral debate about the ends. This idea was taken up in criticisms of the inability of business schools to produce socially responsible leaders (Bennis \& O’Toole, 2005; Khurana, 2007) and for propagating ideologically-inspired amoral theories that absolve students from any sense of moral responsibility (Ghoshal, 2005).

In the 1990s, based on a need to challenge the "neutrality or virtue of management as selfevident or unproblematical” (Alvesson \& Willmott, 1992, p. 1) and the inequalities in social and organizational life, management educators in the UK, Europe, and Australasia started to engage with the principles of Critical Management Education (CME), which can incorporate reflexivity. As educators, we are facing the challenge of developing more responsible approaches to management education (Perriton \& Reynolds, 2018) that counter the techno-rational managerialist pedagogies so prevalent in the USA. While many business schools across the world have adopted the United Nations' Principles of Responsible Management Education (PRME), the question remains to what extent the principles are truly embedded in programs. In a recent UK study, Millar and Price (2018) turn the reflexive gaze inward as educators, arguing that while PRME has introduced a moral focus in the classroom, it has not encouraged critical reflexivity around the "individualist and self-interested nature of business" (p. 360).

ANN L. CUNLIFFE ${ }^{1}$

ann.cunliffe@fgv.br

ORCID: 0000-0001-9399-7716

${ }^{1}$ Fundação Getulio Vargas, Escola de Administração de Empresas de São Paulo, São Paulo, SP, Brazil 
In her Presidential Address to the Academy of Management, Anne Tsui not only argued that business schools do more harm than good in society, but addressed the research gap between theory and practice, and the "terrible life" (2013, p. 175) faced by young scholars forced towards the homogenization of their work due to the drive to publish in top journals, which are North American. Given the lack of criticality in US education, it is unsurprising that research follows the same frame, that is, a focus on generalization, developing abstract theories, and following a narrow research and writing protocol rather than engaging with real problems in real contexts (Cunliffe, 2018).

Given these criticisms and the plethora of corporate scandals in recent years, which are often linked to questionable work practices, irresponsible decision making, and unethical leadership, how might we re-think how we research, theorize, and teach these issues? I propose that one way is helping our students become more reflexive, and becoming more reflexive ourselves as educators and researchers. Before I define reflexivity, I will first differentiate reflexivity and reflection, which are very different approaches.

\section{REFLECTION AND REFLEXIVITY: DEFINITIONS}

\section{Reflection}

Much of what we teach in Business Schools is based on encouraging our students to become "reflective practitioners." As Dewey (1997) notes, reflection is an "ability to "turn things over,' to look at matters deliberately, to judge whether the amount and kind of evidence requisite for decision is at hand," (pp. 66-67) that is, a balance between analysis and synthesis, concrete and abstract, experiential and experimental (empirical and scientific) thinking. Reflection is conceptualized and enacted as a cognitive process in which we apply logical thinking to analyze a situation and/or ourselves in order to achieve an end result.

Donald Schön (1983) drew on the work of Dewey in his book The Reflective Practitioner, which has been influential in shaping westernized conceptions of a key professional and leadership skill, reflection. He differentiated between reflection-on-action and reflection-in-action. Reflection-on-action involves a retrospective evaluation of a decision, event, or behavior considering what happened, why it happened, and how improvements can be made. Schön argued that practitioners rely on a tacit knowing-inaction, which involves spontaneous actions, decisions, and talk; a knowing that we may not be able to articulate. This knowingin-action may involve a type of thinking commonly referred to as "thinking on your feet," in which we somehow construct an understanding of the situation and function within it. Schön calls this process of construction reflecting-in-action, which involves professionals drawing on cumulative organizational and personal knowledge and practices and using them in "a reflective conversation with the situation" (1983, p. 242). As such, reflection involves learning in and from experience, and in doing so gaining insights into ourselves.

Schön's work is a useful stimulus for viewing professional and management knowledge as an active and contextual practice based on self-awareness and an ongoing review of our experience. It forms a cornerstone of many undergraduate, graduate, and Doctorate programs (Anderson, Gold, Stewart, \& Thorpe, 2015). Pedagogies using case studies, self-assessment questionnaires, problem-based learning, action learning, and so on are oriented towards helping students become more reflective practitioners.

\section{Reflexivity}

Sociological theorists take a broad view of reflexivity as an inevitable condition of our ever-changing uncertain contemporary society. Reflexivity is construed as an ability to examine the relationship between the broader social "field" (in Bourdieu's [2004] terms, structure, networks, relationships) and how knowledge, practices and perceptions, and dispositions and identities are reflexively constructed and contested. Reflexivity goes deeper than reflection in terms of questioning what is or could be taken for granted, what ideologies, assumptions, norms, and so on, underpin practices, policies, texts, actions, and our ability as researchers to represent reality accurately. I argue that there is a fundamental ontological difference between reflection and reflexivity. Reflection is based on the objectivist assumption that there is a world out there, which we are separate from, and that through reflection we can identify the structures, patterns, roles, and principles that impact what goes on and how things work. For example, we give our students self-assessment questionnaires to complete so that they can identify what type of leadership style they have and then compare that to the style they should have, that is, they reflect on themselves and compare themselves to objective social categories. Reflexivity embraces a more subjectivist social constructionist ontology, which assumes that we shape and maintain our social and organizational "realities" in our everyday interactions and 
conversations and in the texts we write. We therefore need to question how we do so: what our assumptions are and how they might impact our behavior, relationships, the language that we use, the way we manage organizations, and conduct our research. Reflexivity is about understanding that we live in a social and natural world, we shape it in intended and unintended ways and we therefore need to accept responsibility for what we do and say (Cunliffe, 2016).

I argue that reflexivity can take both critically and selfreflexive forms. Self-reflexivity involves "a dialogue with self about our fundamental assumptions, values, and ways of interacting. In this dialogue, we question our core beliefs and our understanding of particular events" (Cunliffe \& Jun, 2005, p. 229). Self-reflexivity helps us to recognize how our own practices and ways of relating impact how we and others construct social and organizational "realities." Critical reflexivity examines normalizing, disciplining, hegemonic, and exclusionary ideologies, practices, policies, and language in organizations. In doing so, we can change systemic control structures that reproduce themselves in our discourse and practices. Archer (2007) discusses reflexivity as an internal conversation in which we evaluate our social and institutional contexts as a means of circumventing structural constraints.

To summarize, reflection is conceptualized and enacted as a cognitive process in which we apply logical thinking to an analysis of a situation and/or to ourselves in order to achieve an end result. It requires us to reflect on an external world. Reflexivity requires us to recognize that we are embedded in and shape, with others, our lived organizational and social experience and therefore need to question how we do so. It involves turning our gaze on ourselves as educators, researchers, students, managers, and leaders. Therefore, while reflection moves us from perplexity to equilibrium/certainty, reflexivity moves us from equilibrium/ certainty to doubt to new possibilities.

\section{Reflexivity and organization studies research}

Over the last 30 years, Organization studies scholars have been researching ways to bring reflexivity into research. Its development can be traced within two main fields: sociologically oriented work (mainly US based), and philosophically oriented work, in particular, poststructuralism (mainly Europe based). Each orientation leads to different approaches to reflexivity; sociologically oriented work leads to constructionist approaches, and philosophically oriented work leads to deconstructionist approaches.
The sociological (and later phenomenological) reflexive turn was inspired by Clifford and Marcus's (1986) book, Writing Culture, in which a number of authors challenged conventional conceptions of social reality and knowledge and the core values, epistemological principles, and aim of mainstream social science to provide an absolute, objective view of the world. In particular, they argued that we need to acknowledge that science is a historical, political, and linguistic process, that research accounts are allegorical and "true fictions," and that researchers should no longer speak with authority about the lives of others.

The philosophical roots of reflexivity are often linked with the "postmodern" crisis of representation and draws upon philosophers such as Derrida (1976) and Foucault (1970,1972) to deconstruct texts, the relationship between knowledge and power, and challenge normalizing discourses and practices (Chia, 1996) and the need to critique ideologies. Furthermore, it also aims to question knowledge, truth claims, and knowledge/power relationships, to surface normalizing and potentially colonizing processes within society and its institutions, and to interrogate the performativity of language with the aim of examining intended and unintended consequences.

The sociological approach inspires us to be more reflexive about the assumptions underpinning our research strategies, practices, and our identity as researchers (e.g., Alvesson, Hardy, \& Harley, 2008; Cunliffe, 2003; Thomas, Tienari, Davies, \& Meriläinen, 2009). This has led to the development of more reflexive and ethical research methodologies and methods. Organization studies researchers have examined a range of reflexive methodologies including narrative and action research methodologies (e.g., Hibbert, Sillince, Diefenbach, \& Cunliffe, 2014; Ripamonti, Galuppo, Gorli, Scaratti, \& Cunliffe, 2016). They have also explored the relationship between researchers and research subjects as political and co-constructed, requiring a researcher to be self-reflexive about their positioning and relationships in the field (e.g., Cunliffe \& Karunanayake, 2013; McDonald, 2013). There are also studies on how managers and leaders enact reflexivity in practice. For example, Maclean, Harvey, and Chia (2012) draw on Bourdieu's (1990) work around reflexivity to examine how elite business leaders in the UK engage in reflexive practices to recreate themselves. They propose two forms of reflexive practice: accumulative (accumulating capital, positions, and perspectives) and re-constructive (re-creating themselves).

Critical management studies scholars utilize postmodern and poststructuralist forms of reflexivity in their work, recognizing that knowledge is neither politically or ideologically neutral because it can be complicit with what can be experienced as an 
oppressive status quo (Haraway, 1988). Examples of organizational research drawing on this form of reflexivity include Foucauldian studies of power, governmentality, and disciplinary practices in organizations. A recent example by Vidaillet and Bousalham (2018) builds on Foucault's notion of heterotopia to reconfigure coworking spaces as synotopias. Dallyn (2014) develops an ideological reflexivity arguing that ideological critiques often position the researcher as an objective expert and that the political views of the researcher need to be made explicit when naming what is ideological. Furthermore, Ahl and Marlow (2012) bring reflexive critique in the form of a poststructural feminist analysis of the heteronormative assumptions underpinning entrepreneurship theories.

\section{Reflexivity and teaching in organization studies}

The aim of reflexive management and business education is to help students become reflexive practitioners that are able to examine themselves, their actions, interactions, and the nature of their relationships and to act in more ethical and responsive ways (Hibbert, Callagher, Siedlok, Windahl, \& Kim, 2019). The issue of making reflexivity relevant to students can be challenging at both the undergraduate and graduate level. At the Executive MBA level, students are often senior managers in positions of influence in their organizations and deeply enmeshed in prevailing managerial ideologies, structures of control, and systems of power. Undergraduate students often do not have experience of working in organizations but are familiar with hierarchical structures. Questioning these taken-for-granted systems can often be perceived as threatening and needless and one of the major challenges therefore lies in persuading students of the need to think differently, that is, more critically, about their role and their place in society. The challenge can become particularly acute if students expect to be given tools to simplify their lives.

Reflexivity is not about giving students tools and techniques, but about engaging them in both self- and critical reflexivity. $A$ number of management educators have explored how we might do this (e.g., Cunliffe, Aguiar, Góes, \& Carreira, in press; Eriksen, 2012). Dehler (2009) moves towards reflexivity explaining how he develops students as "critical beings" through an experiment in critical action. In doing so, he practices reflexivity in the classroom by creating "a learning space that was genuinely open to the student voice; raise student consciousness to the problematics of globalization and then create the potential for the classroom as a site for social change" (p. 39). Vu and Burton (2019) examine how spiritual practice and moral reflexivity encourage transformative learning. Finally, Allen, Cunliffe and Easterby-Smith (2019) draw on radical reflexivity in relation to sustainability as a means of understanding how "business, communities, and people exist interdependently through their social-material relations" (p. 788) and the implications for management education.

At the undergraduate level we can engage students in reflexivity by encouraging them to explore moments in which they are "struck" (Cunliffe, 2002), a process of reflexive learning by both researcher and research participants that Corlett (2013) extended to learning in research. She defined being struck as "a spontaneous sensation, which occurs in a sticky or striking moment, which triggers an individual to make sense of an experience" (p. 456). Such moments can help students engage in a reflexive conversation with themselves.

\section{CONCLUSION}

In conclusion, I argue that reflexivity is important to organization studies because it helps us, as researchers, to generate rich, complex, and potentially transformational explanations of organizations and organizational life by embracing more pluralistic forms of knowledge. Reflexivity encourages us to think about the impact of our assumptions on research and knowledge production; who we may be privileging and who we may be excluding, what voices we may be silencing, and what impact our theories may have. We can facilitate alternative ways of seeing, being, and acting as managers and leaders by encouraging our students to become more reflexive. Reflexivity is therefore important in addressing the critiques of business schools by helping shape responsible and ethical practice in knowledge generation, education, research, and management practice. Importantly, it can alert us to the need to create and maintain ethical relationships.

\section{REFERENCES}

Ahl, H., \& Marlow, S. (2012). Exploring the dynamics of gender, feminism, and entrepreneurship: advancing debate to escape a dead end? Organization, 19(5), 543-562. doi: 10.1177/1350508412448695

Allen, S., Cunliffe, A. L., \& Easterby-Smith, M. (2019). Understanding sustainability through the lens of radical-reflexivity. Journal of Business Ethics, 154(3), 781-795. doi: 10.1007/s10551-016-3420-3

Alvesson, M., Hardy, C., \& Harley, B. (2008). Reflecting on reflexivity: Reflexive textual practices in organization and management theory. Journal of Management Studies, 45(3), 481-498. doi: 10.1111/j.1467$6486.2007 .00765 . x$ 
Alvesson, M., \& Willmott, H. (Eds.) (1992). Critical management studies. London, UK: Sage

Anderson, L., Gold, J., Stewart, J., \& Thorpe, R. (Eds.). (2015). A guide to professional doctorates in business and management. London, UK: Sage.

Archer, M. S. (2007). Making our way through the world: Human reflexivity and social mobility. Cambridge, UK: Cambridge University Press.

Bennis, W. G., \& O’Toole, J. (2005). How business schools lost their way. Harvard Business Review, 83, 96-104.

Bourdieu, P (1990) In other words: Essay toward a reflexive sociology. Palo Alto, CA: Stanford University Press.

Chia, R. (1996). The problem of reflexivity in organizational research: Towards a postmodern science of organization. Organization, 3(1), 31-59. doi: 10.1177/135050849631003

Clifford, J., \& Marcus, G. (Eds.). (1986). Writing culture: The poetics and politics of ethnography. Berkeley, USA: University of California. Press.

Corlett, S. (2013). Participant learning in and through research as reflexive dialogue: Being 'struck' and the effects of recall. Management Learning, 44(5), 453-469. doi: 10.1177/1350507612453429

Cunliffe, A. L. (2002). Reflexive dialogical practice in management learning. Management Learning, 33(1), 35-61. doi: $10.1177 / 1350507602331002$

Cunliffe, A. L. (2003). Reflexive inquiry in organization research: Questions and possibilities. Human Relations, 56(8), 983-1003. doi: 10.1177/00187267030568004

Cunliffe, A. L. (2016). Republication of 'On becoming a critically reflexive practitioner'. Journal of Management Education, 40(6), 747-768. doi: $10.1177 / 1052562916674465$

Cunliffe, A. L. (2018). Wayfaring: A scholarship of possibilities. Or let's not get drunk on abstraction.M@n@gement, 21, 1429-1439.

Cunliffe, A. L., Aguiar, A. C., Góes, V., \& Carreira, F. (forthcoming, 2020). Reflexivity and transdisciplinarity as paths to developing responsible management education. In D. C. Moosemayer, O. Laasch, C. Parkes, \& K. Brown. (Eds.), The Sage handbook of responsible management learning and education. London, UK: Sage.

Cunliffe, A. L., \& Jun, J. (2005). The need for reflexivity in public administration. Administration and Society, 37(2), 225-242. doi: 10.1177/0095399704273209

Cunliffe, A. L., \& Karunanayake, G. (2013). Working within hyphenspaces in ethnographic research: Implications for research identities and practice. Organizational Research Methods, 16(3), 364-392. doi: $10.1177 / 1094428113489353$

Dallyn, S. (2014). Naming the ideological reflexively: Contesting organizational norms and practices. Organization, 21(2), 244-265. doi: $10.1177 / 1350508413475494$

Dehler, G. (2009). Prospects and possibilities of critical management education: Critical beings and a pedagogy of critical action. Management Learning, 40(1), 31-49. doi: 10.1177/1350507608099312
Derrida, J. (1976). Of grammatology. Baltimore, USA: John Hopkins University Press.

Dewey, J. (1997). How we think. Mineola, USA: Dover Publications, Inc. (originally published 1910).

Eriksen, M. (2012). Facilitating authentic becoming. Journal of Management Education, 36(5), 698-736. doi: $10.1177 / 1052562911423883$

Foucault, M. (1970). The order of things: An archaeology of the human sciences. London, UK: Routledge.

Foucault, M. (1972). The archaeology of knowledge. Trans. by A. M. Sheridan Smith. New York, USA: Pantheon Books.

Ghoshal, S. (2005). Bad management theories are destroying good management practices. Academy of Management Learning and Education, 4(1), 75-91.

Haraway, D. (1988). Situated knowledges: The science question in feminism and the privilege of partial perspective. Feminist Studies, 14, 575-599. doi: $10.2307 / 3178066$

Hibbert, P., Callagher, L., Siedlok, F., Windahl, C., \& Kim, H. S. (2019). (Engaging or avoiding) Change through reflexive practices. Journal of Management Inquiry, 28(2), 187-203. doi: $10.1177 / 1056492617718089$

Hibbert, P., Sillince, J., Diefenbach, T., \& Cunliffe, A. L. (2014). Relationally reflexive practice: A generative approach to theory development in qualitative research. Organizational Research Methods, 17(3), 278 298. doi: $10.1177 / 1094428114524829$

Khurana, R. (2007). From higher aims to hired hands, the social transformation of American business schools and the unfulfilled promise of management as a profession. Princeton, USA: Princeton University Press.

Maclntyre, A. (1981). After virtue: A study in moral theory. Notre Dame, USA: University of Notre Dame Press.

Maclean, M., Harvey, C., \& Chia, R. (2012). Reflexive practice and the making of elite business careers. Management Learning, 43(4), 385 404. doi: $10.1177 / 1350507612449680$

McDonald, J. (2013). Coming out in the field: A queer reflexive account of shifting researcher identity. Management Learning, 44(2), 127-143. doi: $10.1177 / 1350507612473711$

Millar, J., \& Price, M. (2018). Imagining management education: A critique of the contribution of the United Nations PRME to critical reflexivity and rethinking management education. Management Learning, 49(3), 346-362. doi: 10.1177/1350507618759828

Perriton, L., \& Reynolds, M. (2018). Critical management education in challenging times. Management Learning, 49(5), 521-536. doi: $10.1177 / 1350507618795090$

Ripamonti, S., Galuppo, L., Gorli, M., Scaratti, G., \& Cunliffe, A. L. (2016). Pushing action research towards reflexive practice. Journal of Management Inquiry, 25(1), 55-68. doi: 10.1177/1056492615584972

Schön, D. A. (1983). The reflective practitioner: How professionals think in action. New York, USA: Basic Books. 
Thomas, R., Tienari, J., Davies, A., \& Meriläinen, S. (2009). Let's talk about "us" a reflexive account of a cross-cultural research collaboration. Journal of Management Inquiry, 18(4), 313-324. doi: $10.1177 / 1056492608324457$

Tsui, A. S. (2013). On compassion in scholarship: Why should we care? Academy of Management Review, 38(2), 167-180.
Vu, M. C., \& Burton, N. (2019). Mindful reflexivity: Unpacking the process of transformative learning in mindfulness and discernment. Management Learning. doi: 10.1177/1350507619888751

Vidaillet, B., \& Bousalham, Y. (2018). Coworking spaces as places where economic diversity can be articulated: Towards a theory of syntopia. Organization. doi: 10.1177/1350508418794003

\section{AUTHORS' CONTRIBUTIONS}

The author declare that they participated in all stages of development of the manuscript. From the conceptualization and theoretical-methodological approach, as well the theoretical review (literature survey), and finally, writing and final review the article. 